\title{
8
}

\section{imp partilm}

[Recensão a] Dumit, J. 2004 - Picturing personhood: brain scans and biomedical
identity

Autor(es): $\quad$ Sousa, Liliana Gil

Publicado por: CIAS - Centro de Investigação em Antropologia e Saúde

URL persistente:

URI:http://hdl.handle.net/10316.2/29135

DOI:

DOI:http://dx.doi.org/10.14195/2182-7982_25_14

Accessed : $\quad$ 26-Apr-2023 13:48:02

A navegação consulta e descarregamento dos títulos inseridos nas Bibliotecas Digitais UC Digitalis, UC Pombalina e UC Impactum, pressupõem a aceitação plena e sem reservas dos Termos e Condições de Uso destas Bibliotecas Digitais, disponíveis em https://digitalis.uc.pt/pt-pt/termos.

Conforme exposto nos referidos Termos e Condições de Uso, o descarregamento de títulos de acesso restrito requer uma licença válida de autorização devendo o utilizador aceder ao(s) documento(s) a partir de um endereço de IP da instituição detentora da supramencionada licença.

Ao utilizador é apenas permitido o descarregamento para uso pessoal, pelo que o emprego do(s) título(s) descarregado(s) para outro fim, designadamente comercial, carece de autorização do respetivo autor ou editor da obra.

Na medida em que todas as obras da UC Digitalis se encontram protegidas pelo Código do Direito de Autor e Direitos Conexos e demais legislação aplicável, toda a cópia, parcial ou total, deste documento, nos casos em que é legalmente admitida, deverá conter ou fazer-se acompanhar por este aviso.

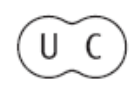




\section{Antropologia Portuguesa}

Volume $24-25 \cdot 2007-2008$

Departamento de Antropologia | Universidade de Coimbra

\section{Dossier Temático \\ CLAUDE LÉVI-STRAUSS}


muliplicidade ontológica reclamada: em vez da "verdade" é o "bem" (goodness) que assume a parte de leão de tal configuração ontológica. O pensamento de Mol está aqui, a meu ver, muito próximo do de Richard Rorty. A comunidade não é função da verdade, mas da "solidariedade", e a solidariedade ou o bem público não depende de uma normatividade ad hoc, mas de um trabalho que se realiza na "contingência". Na sua multiplicidade, a ontologia é vária: diferentes modos de determinar a doença (diferentes ontologias) exigem diferentes modos de conceber o "bem". Uma política-do-quê, nos termos em que a coloca Mol, inclui assim a ontologia-enquanto-prática na sua matriz. Tal política não se funda na presunção ontológica e normativa.

Dir-se-ia assim que a pólis só pode ser construída num contexto de afirmação de diferenças.

\section{Luís Quintais}

Departamento de Antropologia

Faculdade de Ciências e Tecnologia

Universidade de Coimbra

Ifgsq@antrop.uc.pt

Dumit, J. 2004. Picturing personhood: brain scans and biomedical identity. Princeton, Princeton University Press, 272 pp. ISBN 978-0691113982.

Inscrito no debate geral sobre os novos desafios colocados pela tecnologia à organização das sociedades, em Picturing personhood: brain scans and biomedical identity, Joseph Dumit utiliza a história e a etnografia para realizar um estudo social das imagens do cérebro produzidas pela técnica PET ("positron emission tomography"). Com o objectivo de seguir alguns dos percursos destas imagens dentro da sua comunidade virtual - corte heurístico que reúne aqueles que interagem activamente com elas, atribuindo-lhes sentidos que podem ser partilhados, contestados, negociados e/ou reinventados contextualmente -, o autor parte da sua produção em laboratório, onde os seus informantes são cientistas e estudantes da área, onde observa as práticas experimentais e a comunicação dos achados, para depois analisar os fenómenos de disseminação, apropriação e recontextualização das imagens em esferas leigas, nomeadamente ao nível da sua utilização (problemática) como provas demonstrativas nos tribunais americanos e da sua apresentação na comunicação social. Assim, Dumit dá conta dos processos de tradução da técnica em política (Latour 1994 e Woolgar, 
1986), e vice-versa, alertando para os perigos da fixação prematura de premissas e de conhecimentos a que estas imagens - aparentemente tão claras, simples e familiares - apelam; é que, apesar de toda a complexidade e controvérsia que envolve a sua produção, leitura e interpretação de potencialidades científicas, as imagens de cérebros produzidas por PET aparecem na cultura popular como isentas de problemas, demonstrando as diferenças químicas, objectivas, entre os indivíduos doentes e os indivíduos normais. Visualmente atraentes, sintéticas e evocadoras de intuições sobre a natureza/diferença humana, as imagens PET funcionam como ícones universais, subjectivos na medida em que despertam processos de identificação entre o leitor e a imagem (“que tipo de cérebro será o meu?"); a serem utilizadas como instrumento retórico - que o são, de facto -, elas não são inocentes.

Esta análise social feita por Dumit é desenhada em dois momentos: introdução aparte, os capítulos segundo e terceiro - "Metaphors, histories, and visions of PET" e "Producing brain images of mind" - incluem as matérias da ciência e do laboratório, as visões concorrentes sobre a PET, assentes em diferentes idiossincrasias sobre as qualidades do trabalho e do progresso científico, e a produção das imagens, do design da experiência à publicação, respectivamente; os capítulos quarto, quinto e sexto - "Ways of seeing brains as expert images", "Traveling images, popularizing brains" e "Conclusion: here is a PET image of a person that shows depression" fazem a deslocação para a situação das imagens na cultura popular, remetendo-se para o espaço do tribunal, para os média e para o universo das representações sobre a natureza humana. Os capítulos são articulados por interlúdios: pequenos textos ou extractos de entrevistas que sintetizam debates anteriores ou por vir, resgatados do terreno. Pretendendo contribuir para a existência de melhores cientistas e leitores de ciência, este texto tem a responsabilidade da divulgação científica e do esclarecimento, um empenhamento social-político claro, realizado através da demonstração das discrepâncias entre as representações de especialistas e as representações públicas, onde a tónica é colocada tanto na manipulação criativa e contextual positiva servem de exemplo os grupos activistas que procuram na PET, e na biologização do comportamento humano, a destigmatização da doença mental e a promessa de uma cura -, quanto nas acções negativas sobre a ordem social, autorizadas por pseudociência - neste caso, a atribuição de inimputabilidade a indivíduos com "cérebros desviantes". Porque uma série de problemas se levantam à utilização desta técnica neuroimagiológica em diagnóstico, a PETscan só pode ser tida como geradora de hipóteses, e não como teste de confirmação. Basicamente, permite visualizar o metabolismo de moléculas, previamente marcadas com isótopos radioactivos, em lâminas de tecidos de indivíduos escolhidos segundo critérios de (a)normalidade 
arbitrários, desempenhando actividades também elas seleccionadas à luz de afirmações contestáveis - nomeadamente a correspondência de determinadas funções a zonas cerebrais e a dedução de que uma maior actividade representa uma maior participação na função. Além das questões críticas envolvidas na selecção - absolutamente minada pela plasticidade cerebral e pela imprecisão sobre quais os factores que devem ser considerados variáveis pertinentes -, temos que existem diferentes arquitecturas de PET, assim como diferentes resoluções e escalas de apresentação adoptadas, de acordo com os diferentes programas de pesquisa em que participam; não existem medidas ou procedimentos standard - "Like many websites on the Internet, the history of PET is still under construction" (Dumit, 2004: 49) -, sendo muitas as áreas a contribuírem, em simultâneo, para a transformação do instrumento, num enorme esforço de coordenação (Mol, 2002). Por tudo isto, a experiência PET não é replicável, constituindo, portanto, mais um instrumento auxiliar de pesquisa do que uma revolução tecnológica em neuromedicina (ainda que as opiniões entre cientistas divirjam neste ponto). No entanto, é a partir destas inconsistências e desta situação pré-paradigmática (Kuhn, 1996) que se constrói uma série de equações simbólicas que fazem equivaler "scan, tipo de cérebro, tipo de pessoa", no espaço público. Através da prática de publicação de "extreme images", pelos especialistas, como forma de suporte ao texto, reificam-se relações de causa-efeito e tipos, dentro da comunidade virtual da PET. Como Dumit demonstra, num senso público marcado pela semiótica cultural do primado das máquinas, do automático e do objectivo sobre o humano subjectivo, as prioridades texto/imagem invertem-se, sendo a confiança deslocada para a última em detrimento do primeiro - e é assim que, nos tribunais americanos, a força da imagem supera a do especialista. Existe um poder persuasivo na objectividade que é difícil de desconstruir; imparcial, desinteressada, verdadeira e replicável, a representação científica impõe consenso. No caso das imagens de cérebro obtidas por PET em esferas leigas, mais que impor consenso, elas corroboram de forma aparentemente evidente a intuição da diferença entre o normal e o louco, realizando o sonho da distinção automática entre o nós e o outro. São, então, as teias da identificação que estão postas em marcha, a interpretarem culturalmente uma hipótese como uma verdade científica e a fabricarem, a partir disso, novas construções sociais - da arte à política, da fantasia ao julgamento e ao activismo. Como disse, estas imagens não são inocentes.

Mas como interpretar a relevância que um empreendimento monetário e interdisciplinar como a PET assume na sociedade actual, tendo em conta as suas limitações enquanto instrumento de soluções? Ainda que esta não seja uma reflexão adoptada explicitamente, Joseph Dumit oferece uma pista interessante para pensar o fenómeno: 
a noção de "objective self-fashioning". Segundo o autor, a "objective self-fashioning" é uma estratégia de objectivação do "eu" que recorre ao conhecimento científico - ou pelo menos a parte dele, utilizado de forma dinâmica e contextual - para dar significado à existência. Corpo, capacidades, intelecto e outras dimensões da pessoa são formuladas em função de referências científicas privilegiadas, seleccionadas pelas suas qualidades retóricas em diálogo com uma semiótica cultural mais vasta. Constrói-se, então, uma teoria da natureza humana, científica e natural, encarnada e operada no quotidiano, para significar e legitimar práticas e discursos. Cada vez mais informadas pela "objective self-fashioning", a categoria de pessoa e a visão do corpo encontram-se num momento de negociação nas sociedades modernas, tendência que expressa não apenas uma concepção biopolítica latente do mundo (Foucault, 1994), mas que vai também ao encontro dos novos fenómenos de reestruturação da ordem social por referência à ciência e à técnica, registados por Paul Rabinow (1996) e Donna Haraway (1991). Alinhada com a mania classificatória que esteve na génese da ciência moderna, nomeadamente das ciências humanas no séc. XIX - que reuniam os princípios da história natural e da sistemática para compreender o "Homem" (Dias, 1995; Foucault, 1994) -, o ideal propósito desta neuroimagiologia é, apesar dos limites referidos, o diagnóstico automático e objectivo das patologias mentais, o mapeamento de regiões cerebrais por função e o estabelecimento de "chemotypes" específicos, relembrando os antigos sonhos da frenologia e os moldes tipologizantes da criminologia de César Lombroso (Lewontin et al., 1984), ou da "anthropologie" de Broca e Topinard (Roque, 2001), agora sofisticados pela tecnologia. Para todos eles trata-se de objectivar cientificamente a natureza humana, estando implícita a vontade de regular e administrar a diferença, estabelecendo a normalidade. São este tipo de práticas que sustentam a biopolítica à maneira foucauldiana, uma orientação do poder para a vida que vem a desenvolver-se desde o séc. XVII nas nossas sociedades, sustentada em conhecimentos científicos (dispositivos de saber-poder), que permitem a constituição de tecnologias racionais para a gestão dos corpos individuais e das populações. Ao favorecer a criação de identidades biomédicas, a PETscan vincula-se com este projecto, promovendo ao mesmo tempo, a par de outras técnicas e saberes modernos, a criação de novas referências, objectivos e formas de acção e organização políticas, num contexto em que as fronteiras entre natureza e cultura se esbatem (neste caso, não pela via da transformação do natural - ainda? -, mas pela da fundamentação da cultura na natureza, em jeito de contínuo): a biossocialidade de Rabinow (1996). Reestruturam-se as sociabilidades e as referências colectivas. Resta saber qual o espaço de um "chemotype" cerebral numa sociedade pós-disciplinar. Aparentemente não projectiva nem preventiva, a PETscan promete apenas o esta- 
belecimento da diferença, a categorização acabada dos indivíduos, não encerrando em si qualquer princípio emancipatório senão o reconhecimento da existência da plasticidade. À partida, uma identidade biomédica deste tipo não se coaduna com as identidades "cyborg” de Haraway (1991) - do futuro, fusionais, dinâmicas, orquestradas em função dos desafios, em tempos e espaços concretos -; é aí que, determinantemente, entram os agentes, numa história de produção-apropriação-reinvenção que ainda agora começou.

\section{Outras referências:}

Dias, J. 1995. Um contributo oitocentista para a divulgação em Portugal do debate europeu sobre a Raça. Ethnologia: racismo e xenofobia, 3-4: 121-137.

Foucault, M. 1994. História da sexualidade I: a vontade de saber. Lisboa, Relógio d'Água.

Haraway, D. 1991. Simians, cyborgs, and women: the reinvention of nature. Londres, Free Association Books Ltd.

Kuhn, T. 1996 (1962). The structure of scientific revolutions. Chicago and London, The University of Chicago Press.

Latour, B. 1997 (1993). We have never been modern. Cambridge, Harvard University Press.

Latour, B.; Woolgar, S. 1986 (1979). Laboratory life: the construction of scientific facts. Princeton, Princeton University Press.

Lewontin, R.; Rose, S.; Kamin, L. 1984. Genética e política. Mem Martins, Publicações Europa-América.

Mol, A. 2002. The body multiple: ontology in medical practice. Durham and London, Duke University Press.

Rabinow, P. 1996. Artificiality and Enlightenment: from sociobiology to biosociality. In: essays on the anthropology of reason, Princeton, Princeton University Press: 91-111.

Roque, R. 2001. Antropologia e império: Fonseca Cardoso e a expedição à Índia em 1895. Lisboa, Imprensa de Ciências Sociais.

\section{Liliana Gil Sousa \\ Departamento de Antropologia \\ Faculdade de Ciências e Tecnologia \\ Universidade de Coimbra \\ lilianagilsousa@hotmail.com}

